\title{
Philadelphia-Negative Myeloproliferative Neoplasms Around the COVID-19 Pandemic
}

\author{
Tiziano Barbui $^{1}\left(\mathbb{D} \cdot\right.$ Valerio De Stefano $^{2}$
}

Accepted: 3 May 2021 / Published online: 29 September 2021

(c) The Author(s), under exclusive licence to Springer Science+Business Media, LLC, part of Springer Nature 2021

\begin{abstract}
Purpose of Review Coronavirus disease 2019 (COVID-19) is associated with a high rate of respiratory failure, thromboembolism, bleeding, and death. Patients with myeloproliferative neoplasms (MPNs) are prone to both thrombosis and bleeding, calling for special care during COVID-19. We reviewed the clinical features of MPN patients with COVID-19, suggesting guidance for treatment. Recent Findings One study by the European LeukemiaNet collected 175 MPN patients with COVID-19 during the first wave of the pandemic, from February to May 2020. Patients with primary myelofibrosis (PMF) were at higher risk of mortality (48\%) in comparison with essential thrombocythemia (ET) (25\%) and polycythemia vera (19\%); the risk of death was higher in those patients who abruptly discontinued ruxolitinib. In patients followed at home, in regular wards, or in ICU, the thrombosis rate was $1.0 \%, 2.8 \%$, and $18.4 \%$, respectively. Independent risk factors for thrombosis were ET phenotype, transfer to ICU, and neutrophil/lymphocyte ratio; major bleeding occurred in $4.3 \%$ of patients, particularly those with PMF. Summary MPN patients with non-severe COVID-19 treated at home should continue their primary or secondary antithrombotic prophylaxis with aspirin or oral anticoagulants. In the case of hospitalization, patients assuming aspirin should add low molecular weight heparin (LMWH) at standard doses. In contrast, LMWH at intermediate/therapeutic doses should replace oral anticoagulants prescribed for atrial fibrillation or previous venous thromboembolism. Intermediate/high doses of LMWH can also be considered in ICU patients with ET, particularly in the case of a rapid decline in the number of platelets and progressive respiratory failure.
\end{abstract}

Keywords Aspirin · Bleeding · COVID-19 $\cdot$ Low molecular weight heparin $\cdot$ Myeloproliferative neoplasms $\cdot$ Thrombosis

\section{Introduction}

The SARS-CoV-2 coronavirus infection causing the coronavirus disease 2019 (COVID-19) is a highly contagious and life-threatening disease. No country, race, ethnicity, or religion is spared

This article is part of the Topical Collection on Myeloproliferative Neoplasms

Tiziano Barbui and Valerio De Stefano equally contributed to this work.

Tiziano Barbui

tbarbui@fondazionefrom.it

Valerio De Stefano

valerio.destefano@unicatt.it

1 FROM Research Foundation, Papa Giovanni XXIII Hospital, Piazza OMS n. 1, 24127 Bergamo, Italy

2 Section of Hematology, Department of Radiological and Hematological Sciences, Catholic University, Policlinico Universitario “A. Gemelli” IRCCS, Rome, Italy from this infection (https://coronavirus.jhu.edu/map.html). All ages are susceptible to COVID-19, and the clinical spectrum appears to be broad. The features of severe COVID-19 are dominated by an acute pneumonic process with extensive radiologic opacity and, on autopsy, diffuse alveolar damage, inflammatory infiltrates, and microvascular thrombosis. Moreover, infected patients are also likely to be at increased risk of venous and arterial thromboembolism, as reported in China [1] and confirmed in autopsies of patients experiencing sudden death [2]. Both elderly and young patients can succumb to death depending on their underlying health conditions such as cardiovascular diseases, kidney damage, liver dysfunction, diabetes, and cancer [3].

\section{MPNs Are at Increased Risk of Infection and Mortality Due to COVID-19}

The risk of getting SARS-CoV-2 infection may vary according to the individual MPN subtype. Only one study by the European LeukemiaNet (ELN) investigators reported the 
clinical epidemiology of COVID-19 in patients with essential thrombocythemia (ET), polycythemia vera (PV), prefibrotic myelofibrosis (pre-PMF), and primary myelofibrosis $(\mathrm{PMF})[4 \bullet \bullet]$. One hundred seventy-five patients with COVID-19 were collected in 38 international hematologic centers during the first wave of the pandemic, from February to May 2020. Among the MPN phenotypes, patients with $\mathrm{PMF}$, including pre-PMF and overt PMF, were the great majority, accounting for $44 \%$ of those reported. This is not surprising due to the natural propensity to get infections in PMF. In a large population-based matched cohort study carried out in Sweden, including 8363 MPN patients and 32,405 controls using high-quality registers, the hazard ratio (HR) of any infection in MPN was 2.0 (bacterial infections HR 1.9, 95\% CI 1.8-2.0 and viral infections HR 2.1, 95\% CI 1.9-2.3). Notably, the HR of any infection was highest in PMF (HR 3.7, 95\% CI 3.2-4.1) and significantly elevated in all MPN subtypes (HR 1.7, 95\% CI 1.6-1.8 in PV and HR $1.7,95 \%$ CI $1.5-1.8$ in ET) [5••].

Many studies have been undertaken regarding hematologic malignancies addressing numerous issues either related to the infection and the underlying hematologic cancer itself. In a recent systematic review and meta-analysis, fatalities were calculated to occur in $34 \%$ of hospitalized adult patients [6•]. Advanced age ( $\geq 60$ years) and non-white race were identified as risk factors for death. Mortality rate varied on the basis of the type of malignancy: 53\% of patients with acquired bone marrow failure syndromes, $41 \%$ of patients with acute leukemias, $33 \%$ of patients with plasma cell dyscrasias, $32 \%$ of patients with lymphomas, $31 \%$ of patients with chronic lymphocytic leukemia, and $34 \%$ of patients with myeloproliferative neoplasms (MPNs) [6•]. These estimates are three-fold higher than those reported in hospitalized patients with COVID-19 of the general population in Europe and the USA [7-9]. When compared with the general population with COVID-19, the mortality ratio in the ELN study [4••] was at least two to three times higher than the mortality rates reported by Johns Hopkins in the same period of the first wave of the pandemic and comparable to that reported in other hematologic malignancies collected in the same period $[6 \bullet, 10 \bullet \bullet]$.

In univariate analysis, age, male gender, decreased lymphocyte counts, need for respiratory support, comorbidities, and diagnosis of PMF showed a significant relationship with death. Patients with MF were at higher risk of mortality (48\%) in comparison with ET (25\%) and PV (19\%). No correlation between the driver mutation genotype and death was found. Regarding MPN-directed therapy ongoing at COVID-19 diagnosis, hydroxyurea (HU) did not show significant correlations. In contrast, multivariable and propensity score matching analyses found an increased risk of death in patients who abruptly discontinued ruxolitinib treatment $[4 \bullet \bullet]$. According to the recommendations of the American
Society of Hematology (https://www.hematology.org/covid19/covid-19-and-myeloproliferativeneoplasmsi), if ruxolitinib needs to be stopped, it should be tapered cautiously (https://www.hematology.org/covid-19/covid-19-and-myelo proliferativeneoplasms).

To optimize the management of MPN patients with COVID-19, the ASH experts are maintaining a webpage to assist hematologists in navigating the COVID-19 public health crisis.

\section{Thrombosis in MPN Without COVID-19: Implications During the Pandemic}

MPN patients are predisposed to thrombosis and bleeding, and these events contribute considerably to morbidity and mortality. Thrombosis can be the first presenting sign preceding the diagnosis of MPN in $20 \%$ of cases, with a persistent risk during the follow-up, where the incidence is the highest in patients with PV (3.5 per 100 patient-years) and similar in ET and PMF (2.5 per 100 patient-years). Particularly in ET, arterial events are more prevalent (70\%) than venous thromboembolic events (VTE), which encompass deep vein thrombosis of the leg or pulmonary embolism and uncommon sites such as splanchnic or cerebral veins [11].

In the most extensive epidemiologic study in PV (i.e., the European Collaboration on Low-dose Aspirin [ECLAP] study), cardiovascular mortality accounted for $45 \%$ of all deaths ( 1.7 deaths per 100 persons per year, with a cumulative incidence of $4.5 \%)$, mainly due to coronary heart disease $(15 \%$ of all deaths), congestive heart failure (8\%), non-hemorrhagic stroke (8\%), and pulmonary embolism $(3.6 \%)$. The cumulative rate of non-fatal thrombosis was $10.3 \%$, without a difference between arterial and venous thrombosis [12]. Of note, in the most recent studies dealing with contemporary patients with PV [13], post-diagnosis total major thrombosis rate was 2.62 per 100 patient-years, a figure lower than that reported in the ECLAP trial but comparable to the one in the more recent randomized clinical trial Cyto-PV where the rate was 2.7 per 100 patient-years [14]. In prospective studies in ET, fatal and non-fatal thrombotic events ranged from 0.9 to 2.6 per 100 patient-years. The incidence of arterial events was 2 to 3 times higher than that of venous events [15-17].

In PMF, the prevalence of major thrombosis was assessed in 707 patients, followed in 4 European institutions. The overall cumulative rate of cardiovascular death and non-fatal thrombotic complications, corrected by competing for risk for mortality, was 2.23 events per 100 persons per year. No significant difference between non-fatal venous and arterial thrombosis was registered $(0.76 \%$ and $0.86 \%$ patients per year, respectively) [18]. 
A recent population-based study carried out in Sweden recruiting 9429 patients with MPNs and 35,820 matched control from 1987 to 2009, with follow-up to 2010, found that the HRs for arterial thrombosis among patients with MPNs compared with controls at 3 months, 1 year, and 5 years were 3.0 (95\% CI 2.7-3.4), 2.0 (95\% CI 1.8-2.2), and 1.5 (95\% CI 1.4-1.6), respectively. The corresponding HRs for venous thrombosis were 9.7 (95\% CI 7.8-12.0), 4.7 (95\% CI 4.0-5.4), and 3.2 (95\% CI 2.9-3.6). The rate was significantly elevated across all age groups and was similar among MPN subtypes [19].

Since the risk of thrombosis in ET and PV varies substantially between patients, a personalized treatment based on a risk-stratified approach is recommended by NCCN and ELN guidelines [20,21].

In PV, two risk categories are considered: high (age $>60$ years or thrombosis history present) and low (absence of both risk factors); in ET, the IPSET thrombosis scoring system, four risk categories identify patients at different thrombotic risks according to age, prior thrombosis, cardiovascular risk factors, and the presence of JAK2V617F mutation $[22,23]$. Since the median survival in PMF is $\sim 6$ years, ranging from $<2$ to $>10$ years, the relevant endpoint for current prognostic scoring systems in PMF is represented by survival. However, even though a scoring system of thrombosis is not available in PMF, risk factors were identified and included the presence of JAK2V617F mutation, leukocytosis, and prior vascular events [18].

The implications of these findings during the pandemic in MPN patients without documented COVID-19 infection or symptoms have been considered in the ASH recommendations. The panel of experts suggests strict adherence to current treatment goals aimed at decreasing the risk of thrombosis (HCT $<45 \%$ in PV, antiplatelet therapy in all PV and ET patients if indicated according to the IPSET score, cytoreduction to achieve European LeukemiaNet levels of control (HCT $<45 \%$, leukocytes $<10 \times 10^{9} / \mathrm{L}$, platelets $<400 \times$ $\left.10^{9} / \mathrm{L}\right)$ ).

\section{The Thrombosis Rate in MPN with COVID-19 Varies According to the Phenotype}

To our knowledge, the only study published so far on the incidence and risk factors of thrombosis and bleeding in MPN was conducted by the European LeukemiaNet and involved 162 patients, with ET $(n=48)$, PV $(n=42)$, PMF $(n=56)$, and pre-PMF $(n=16)$. Twenty-two episodes of major thrombosis $(n=15)$ and major bleedings $(n=7)$ occurring during the acute phase of the first wave of coro-

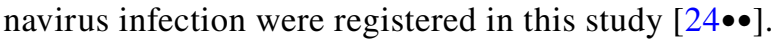

Thromboses were reported in patients managed at home, during hospitalization in regular wards, or in intensive care units (ICU). Overall, only three arterial thromboses were documented whereas the majority were VTE $(n=12)$ detected with a significantly higher frequency in ET patients $(n=8 / 48,16.7 \%)$ than in PV $(n=2 / 42,4.8 \%)$ or $\operatorname{MF}(n=2 / 56,3.6 \%)(p=0.031)$. All but two patients with VTE were receiving anticoagulation with low molecular weight heparin (LMWH) at low/intermediate $(50 \%)$ or therapeutic doses $(n=50 \%)$.

Adjusting the competing risk of dying, the probability of total thrombosis progressively increased in the first month after COVID-19 diagnosis and reached $8.5 \%$ after 60 days of follow-up (Fig. 1). The cumulative incidence rate at 10, 20 , and 30 days was $4.1 \%, 5.9 \%$, and $7.1 \%$, respectively. In patients followed at home or in the regular ward, the rate was $1.0 \%$ and $2.8 \%$, respectively, whereas it reached $18.4 \%$ in the 17 (10\% of the entire cohort) ICU patients. The effects of possible predictors of thrombosis, selected from those clinically relevant and statistically significant in univariate analysis, were examined in a multivariate model. Independent risk factors were transfer to ICU (subdistribution hazard ratio $[\mathrm{SHR}]=3.73, p=0.029$ ), neutrophil/lymphocyte ratio $(\mathrm{SHR}=1.1, p=0.001)$, and ET phenotype $(\mathrm{SHR}=4.37$, $p=0.006)[24 \bullet \bullet]$.

Overall, these findings in MPN patients are hardly comparable with those reported in the general population, where the incidence rate largely depends on whether patients are specifically screened for the presence of thrombosis or only considers symptomatic thrombosis. This variability is exemplified either in observational studies or in systematic reviews and meta-analyses. One of the first investigations reported that patients followed in ICU and screened for thrombosis presented VTE in 39 of $75(47 \%)$ [25••], a figure two-fold higher than in the MPN. This high rate was confirmed in a recent meta-analysis. A subgroup of 2500 patients utilizing systematic screening revealed a VTE prevalence of almost $50 \%$ of critically ill patients who received prophylactic or therapeutic LMWH doses [26].

Conversely, in a multicenter retrospective study, 400 hospital-admitted COVID-19 patients (144 critically ill) managed in the real-world clinical practice and treated with prophylactic LMWH doses had symptomatic VTE in $7.6 \%$ and $4.8 \%$ in ICU or regular wards, respectively $[27 \bullet \bullet]$. This frequency was also confirmed in one of the latest meta-analysis. The incidence of VTE in critically ill patients was $8 \%$ for clinically relevant pulmonary embolism and $14 \%$ for proximal deep vein thrombosis [28]. These figures are substantially lower than those determined in other previous meta-analyses [29] and underscore the difficulty of making reliable comparisons with the estimates found in MPN.

On the other hand, the classic venous and arterial thromboses represent only part of the vascular problem in the context of COVID-19, in which multiple micro-thromboses in 
Fig. 1 Cumulative incidence of thrombosis and bleeding during the acute phase of COVID-19, overall and by MPN phenotypes

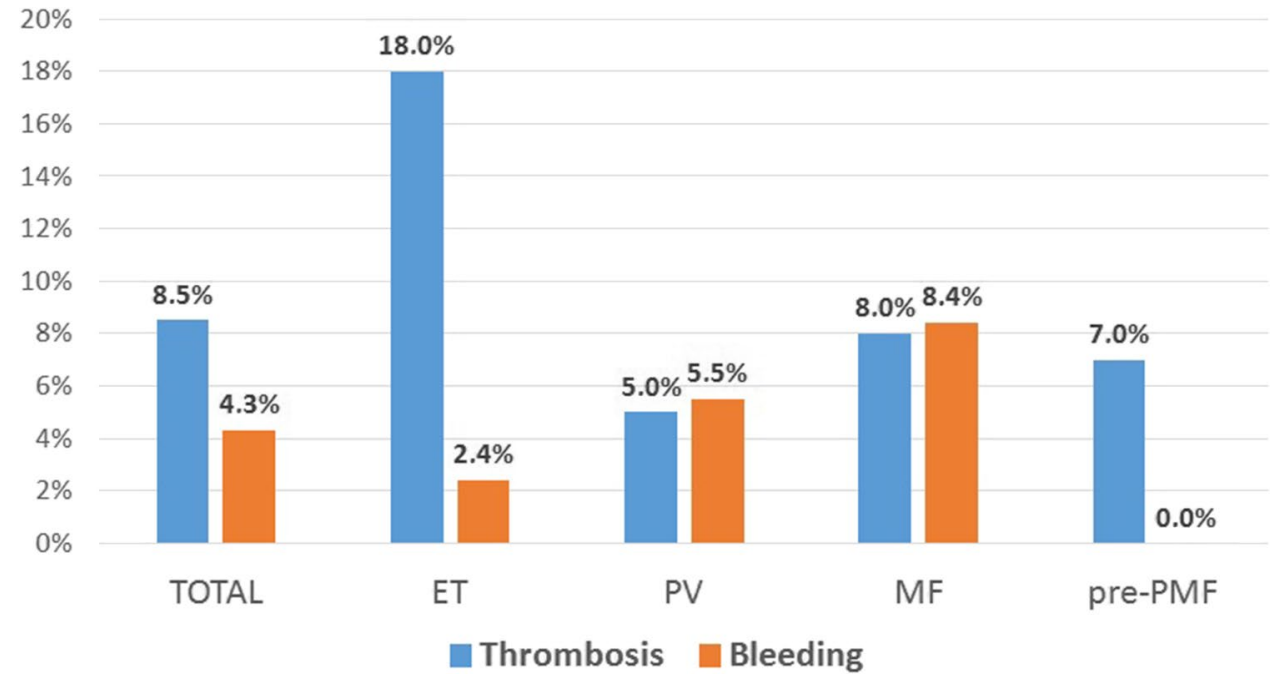

$6.9 \%$ in PV [11]. During the follow-up, up to $4 \%$ of MPN patients have a hemorrhagic complication within the first decade after diagnosis [33].

During COVID-19, the ELN study reported 7 of 162 (4.3\%) patients who developed major bleeding, particularly in MF, where all the hemorrhagic episodes required blood transfusions (Fig. 1). These estimates are slightly higher than that reported (2.3\%) in the general population with COVID-19 $[27 \bullet \bullet]$. Interestingly, while the peak of thrombotic events occurred in the first days after COVID-19 diagnosis, bleeding episodes were reported later, starting 2 weeks afterward. Of note, in 4 of the 7 cases, coagulopathy or severe thrombocytopenia was associated with severe bleeding, suggesting caution on the empiric intensification of LMWH, particularly in PMF

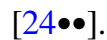

\section{Antithrombotic Prophylaxis and Treatment of MPN Patients with COVID-19}

\section{Low Molecular Weight Heparin (LMWH) in the General Population}

To prevent VTE, guidelines from international scientific organizations recommended anticoagulant thromboprophylaxis with LMWH in all hospitalized COVID-19 patients in the absence of contraindications $[34,35 \bullet, 36 \bullet$, $37 \bullet, 38]$. Nevertheless, since the beginning of the pandemic, clinicians had the perception that standard dosages of this drug were not adequate to prevent VTE in patients with COVID-19 and higher LMWH doses were proposed $[25 \bullet \bullet, 39,40]$.

Advantages of LMWH prophylaxis were quantitatively documented in a meta-analysis on 25,719 hospitalized COVID-19 patients, in whom a 50\% reduction of 
in-hospital mortality was shown (pooled risk ratio, RR $0.50,95 \%$ CI $0.40-0.62$ ). Interestingly, in ICU patients, a substantial reduction of the thrombotic rate was ascertained when LMWH was administered at therapeutic dosage compared to the prophylactic one. In-hospital mortality decline was demonstrated (RR: $0.30,95 \%$ CI: $0.15-0.60 ; I 2: 58 \%)$. However, new evidence from the REMAP-CAP randomized controlled trial indicates that for patients with severe disease who required ICU support, therapeutic anticoagulation did not improve outcomes and increased bleeding risk [41•].

Given the safety concern, the empiric use of full-dose LMWH is discouraged outside of a clinical trial, even in critically ill MPN patients with COVID-19, such as the subgroup with ET who would typically be admitted to an ICU. The approach of administering intermediate regimens of LMWH in high-risk MPN with COVID19 patients may be considered in particular high-risk patients with high-risk features and rapid respiratory deterioration while on prophylactic LMWH dose. This was not confirmed in the REMAP-CAP randomized controlled trial in which ICU patients with severe COVID19 receiving therapeutic anticoagulation did not improve and substantially increased the bleeding risk.

In the INSPIRATION study that enrolled 600 patients admitted to the ICU with COVID-19, prophylaxis with intermediate-dose anticoagulation, compared with the standard-dose, failed to show a significant difference in a composite endpoint of venous or arterial thrombosis, treatment with extracorporeal membrane oxygenation, or mortality within 30 days [42••]. Thus, based on this latter result, the routine empirical use of intermediate-dose prophylactic anticoagulation in unselected patients admitted to the ICU with COVID-19 is not recommended in the general population.

\section{Low Molecular Weight Heparin (LMWH) in MPN Patients}

It is complicated to compare these data obtained in the general population with SARS-CoV-2 infection of patients with MPN. The only study that details the efficacy risk profile of heparin prophylaxis in MPN with COVID-19 concerns only 162 patients, of which 19 experienced 22 thrombo-hemorrhagic events at home $(n=1 / 40,2.5 \%)$, or during hospitalization in regular wards $(n=13 / 105$, $12.4 \%)$ or in ICU $(n=5 / 17,29.4 \%)(p=0.016)$. All but two patients with VTE were receiving LMWH anticoagulation with low/intermediate $(n=5 / 10,50 \%)$ or therapeutic doses $(n=5 / 10,50 \%)$. Mortality was recorded in 7 of 14 $(50 \%)$ patients with thrombosis, of which one was attributed to acute myocardial infarction. At the same time, the other six were not considered to be related to the vascular events $[24 \bullet \bullet]$.

Therefore, we believe that, in line with the recommendations contained in the latest ASH version of the international panel of MPN experts [43], all hospitalized patients should receive prophylactic doses of LMWH.

In Fig. 2, some scenarios are presented that affect patients with MPN and COVID-19 stratified according to their history of thrombosis and treated at home or in hospital. In the case of non-severe COVID-19, antithrombotic regimen prophylaxis is that recommended independently on COVID-19. In contrast, in patients with medium/high severity of the infection, prevention can be diversified, and, in some cases, MPN patients with COVID-19 may need higher doses of heparin.

High-risk condition concerns hospitalized patients with MPN treated with both anti-vitamin-K antagonists (VKA) or direct oral anticoagulants (DOACs) for pre-COVID-19 VTE chronic atrial fibrillation. In these cases, depending on the severity of the COVID-19 and patient circumstances, oral anticoagulants could be replaced with intermediate/therapeutic doses of heparin. If the patient's condition with MPN-COVID allows it, the question may arise to continue VKA or DOACs even during the acute phase of the infection. However, given the possible interaction of these drugs with most antiretroviral drugs on liver cytochromes, such as CYP2C9 and CYP3A4, the advice is to replace oral anticoagulants with LMWH prophylaxis.

Intermediate/high doses of heparin can also be considered in ICU patients with ET associated with a rapid decline of the number of platelets and progressive respiratory failure, mainly if the clinical worsening had arisen despite the use of heparin at prophylactic doses. Notably, the higher incidence of VTE observed in ET than PV and PMF was associated with higher mortality risk and may justify some risks of bleeding.

\section{The Role of Aspirin During the Acute Phase of Infection}

In addition to its antithrombotic efficacy, aspirin was shown to reduce the risk of ARDS mortality [44]. This impact might not be due to the antithrombotic action but rather to its antiviral and anti-inflammatory properties, which are not possessed by other antiplatelet drugs [45•]. Moreover, a study showed that aspirin users exhibited a quicker recovery of the acute phase of the infection in comparison with non-users $(p=0.045)$, a less frequent need of mechanical ventilation (adjusted HR $0.56,95 \%$ CI $0.37-0.85, p=0.007$ ), ICU admission (adjusted HR 0.57, 
Fig. 2 Flow chart of antithrombotic prophylaxis in patients with myeloproliferative neoplasms and COVID-19

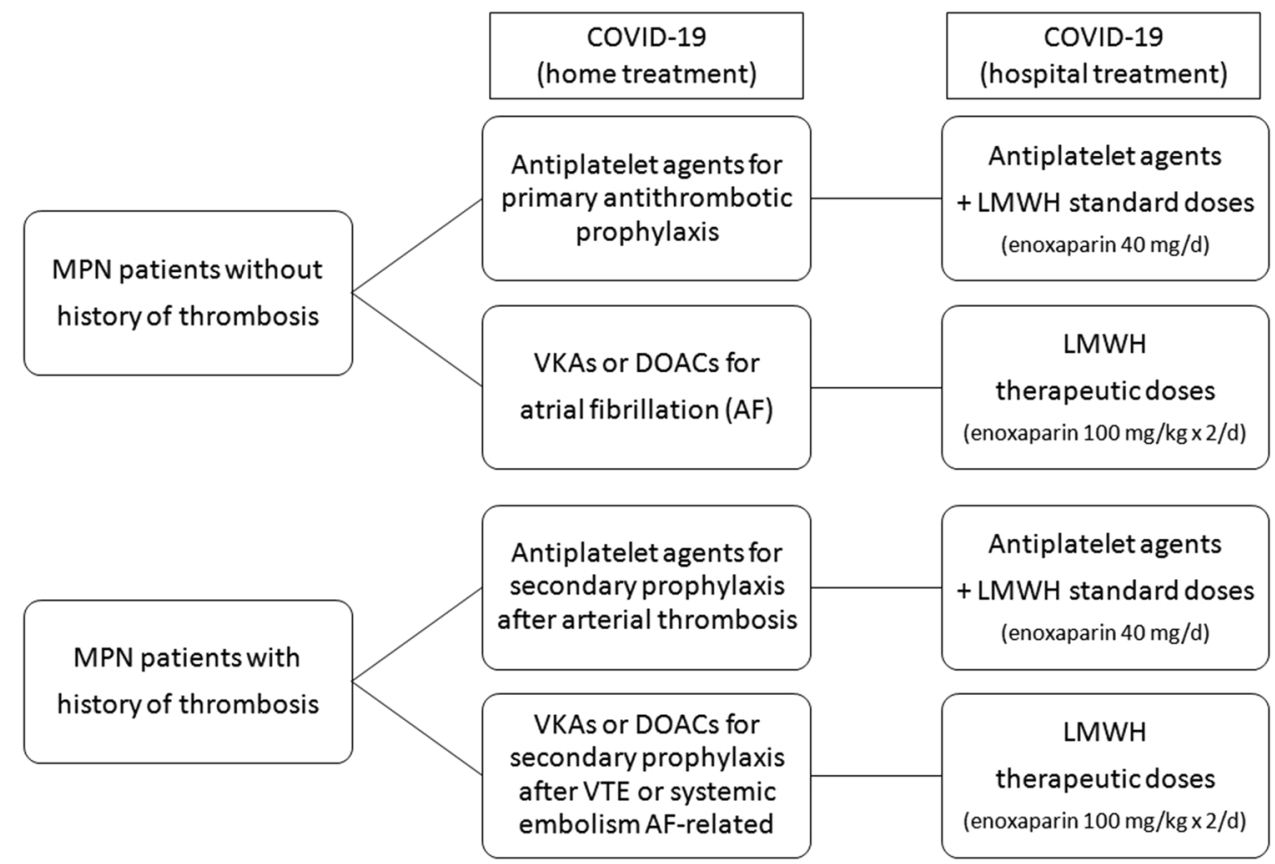

95\% CI $0.38-0.85, p=0.005)$, and in-hospital mortality (adjusted HR 0.53, 95\% CI 0.31-0.90, $p=0.02$ ). Most importantly, no excess of major bleeding was documented $(p=0.69)[46 \bullet \bullet]$.

These findings will have to be exploited in the prophylaxis of thrombosis in patients with MPN, particularly in ET, given its higher incidence of venous events during COVID-19. Unfortunately, it will be difficult to conduct appropriate comparative intervention studies in this setting due to the rarity of these diseases. However, the use of aspirin could be proposed, even in the association with LMWH unless contraindications, occurring during in-hospital stay (acute liver failure, severe renal failure, severe thrombocytopenia, documented drug interactions, planned invasive procedures).

In patients with pre-COVID-19 arterial thrombosis (transient ischemic attack, ischemic stroke, myocardial infarction, peripheral arterial thrombosis) or with percutaneous coronary intervention (PCI) (within $\leq 3$ months), it is strongly recommended not to discontinue antiplatelet drugs, unless clinical circumstances or hemorrhagic events prevent it [47].

Since thrombocytopenia is a frequent finding during COVID-19 and particularly in PMF and in 23\% of patients is severe (under $50 \times 10^{9} / \mathrm{L}$ ) [24••], strict monitoring of the platelet count is warranted, particularly in MPN patients in need of cytoreductive therapy.

\section{Conclusion}

Venous thromboembolism and arterial thrombosis constitute a significant concern in some categories of patients with SARS-CoV-2 infection. Although the available data is scarce, an association between ET and thrombosis, regardless of inflammation indicators and the severity of COVID19, was shown. Moreover, bleeding is mainly reported in MF. The limited incidence of thrombotic events did not allow to produce robust evidence on the use of heparin or antiplatelet drug prophylaxis. Therefore, we must draw some considerations and suggestions based on the evidence produced by the numerous studies conducted in the general population. Our advice is in line with ASH recommendations and indicates that MPN patients with COVID-19 treated at home should receive the recommended routine prophylaxis. VKAs or DOACs prescribed for pre-COVID venous thrombosis or atrial fibrillation should be replaced with LMWH at intermediate/therapeutic doses in the case of hospitalization.

Given that MPNs are more prone than other patients to developing heparin-induced thrombocytopenia [48, 49], strict platelet count surveillance is warranted.

\section{Compliance with Ethical Standards}

Conflict of Interest Tiziano Barbui and Valerio De Stefano declare that they have no conflict of interest. 
Human and Animal Rights and Informed Consent This article does not contain any studies with human or animal subjects performed by any of the authors.

\section{References}

Papers of particular interest, published recently, have been highlighted as:

- Of importance

$\bullet$ Of major importance

1. Cui S, Chen S, Li X, Liu S, Wang F. Prevalence of venous thromboembolism in patients with severe novel coronavirus pneumonia. J Thromb Haemost. 2020;18(6):1421-4.

2. Carsana L, Sonzogni A, Nasr A, Rossi RS, Pellegrinelli A, Zerbi P, Rech R, Colombo R, Antinori S, Corbellino M, Galli M, Catena E, Tosoni A, Gianatti A, Nebuloni M. Pulmonary post-mortem findings in a series of COVID-19 cases from northern Italy: a two-centre descriptive study. Lancet Infect Dis. 2020;20(10):1135-40.

3. Mesas AE, Cavero-Redondo I, Álvarez-Bueno C, Sarriá Cabrera MA, Maffei de Andrade S, Sequí-Dominguez I, MartínezVizcaíno V. Predictors of in-hospital COVID-19 mortality: a comprehensive systematic review and meta-analysis exploring differences by age, sex and health conditions. PLoS One 2020;15(11):0241742.

4.•• Barbui T, Vannucchi AM, Alvarez-Larran A, Iurlo A, Masciulli A, Carobbio A, Ghirardi A, Ferrari A, Rossi G, Elli E, AndradeCampos MM, Kabat MG, Kiladjian JJ, Palandri F, Benevolo G, Garcia-Gutierrez V, Fox ML, Foncillas MA, Morcillo CM, Rumi E, Osorio S, Papadopoulos P, Bonifacio M, Cervantes KSQ, Serrano MS, Carreno-Tarragona G, Sobas MA, Lunghi F, Patriarca A, Elorza BN, Angona A, Mazo EM, Koschmieder S, Ruggeri M, Cuevas B, Hernandez-Boluda JC, Abadia EL, Cirici BX, Guglielmelli P, Garrote M, Cattaneo D, Daffini R, Cavalca F, Bellosillo B, Benajiba L, Curto-Garcia N, Bellini M, Betti S, De Stefano V, Harrison C, Rambaldi A. High mortality rate in COVID-19 patients with myeloproliferative neoplasms after abrupt withdrawal of ruxolitinib. Leukemia. 2021;35(2):485-93. A multicenter series of MPN patients with COVID-19 analyzing risk factors for mortality.

5.• Landtblom AR, Andersson TM, Dickman PW, Smedby KE, Eloranta S, Batyrbekova N, Samuelsson J, Björkholm M, Hultcrantz M. Risk of infections in patients with myeloproliferative neoplasms-a population-based cohort study of 8363 patients. Leukemia. 2021;35(2):476-84. A population-based study on the risk of infection in patients with MPN.

6. Vijenthira A, Gong IY, Fox TA, Booth S, Cook G, Fattizzo B, Martín-Moro F, Razanamahery J, Riches JC, Zwicker J, Patell R, Vekemans MC, Scarfò L, Chatzikonstantinou T, Yildiz H, Lattenist R, Mantzaris I, Wood WA, Hicks LK. Outcomes of patients with hematologic malignancies and COVID-19: a systematic review and meta-analysis of 3377 patients. Blood. 2020;136(25):2881-92. A systematic review and meta-analysis of the outcomes of patients with hematological malignancies affected from COVID-19.

7. Onder G, Rezza G, Brusaferro S. Case-fatality rate and characteristics of patients dying in relation to COVID-19 in Italy. JAMA. 2020;323(18):1775-6.

8. Posso M, Comas M, Román M, Domingo L, Louro J, González C, Sala M, Anglès A, Cirera I, Cots F, Frías VM, Gea J,
Güerri-Fernández R, Masclans JR, Noguès X, Vázquez O, Villar-García J, Horcajada JP, Pascual J, Castells X. Comorbidities and mortality in patients with COVID-19 aged 60 years and older in a university hospital in Spain. Arch Bronconeumol. 2020;56(11):756-8.

9. Finelli L, Gupta V, Petigara T, Yu K, Bauer KA, Puzniak LA. Mortality among US patients hospitalized with SARS-CoV-2 infection in 2020. JAMA Netw Open. 2021;4(4):e216556.

10.• Passamonti F, Cattaneo C, Arcaini L, Bruna R, Cavo M, Merli F, Angelucci E, Krampera M, Cairoli R, Della Porta MG, Fracchiolla N, Ladetto M, Gambacorti Passerini C, Salvini M, Marchetti M, Lemoli R, Molteni A, Busca A, Cuneo A, Romano A, Giuliani N, Galimberti S, Corso A, Morotti A, Falini B, Billio A, Gherlinzoni F, Visani G, Tisi MC, Tafuri A, Tosi P, Lanza F, Massaia M, Turrini M, Ferrara F, Gurrieri C, Vallisa D, Martelli M, Derenzini E, Guarini A, Conconi A, Cuccaro A, Cudillo L, Russo D, Ciambelli F, Scattolin AM, Luppi M, Selleri C, Ortu La Barbera E, Ferrandina C, Di Renzo N, Olivieri A, Bocchia M, Gentile M, Marchesi F, Musto P, Federici AB, Candoni A, Venditti A, Fava C, Pinto A, Galieni P, Rigacci L, Armiento D, Pane F, Oberti M, Zappasodi P, Visco C, Franchi M, Grossi PA, Bertù L, Corrao G, Pagano L, Corradini P; ITA-HEMA-COV Investigators. Clinical characteristics and risk factors associated with COVID-19 severity in patients with haematological malignancies in Italy: a retrospective, multicentre, cohort study. Lancet Haematol. 2020;7(10): e737-e745. A multicenter series of patients with hematological malignancies affected from COVID-19.

11. Rungjirajittranon T, Owattanapanich W, Ungprasert P, Siritanaratkul N, Ruchutrakool T. A systematic review and metaanalysis of the prevalence of thrombosis and bleeding at diagnosis of Philadelphia-negative myeloproliferative neoplasms. BMC Cancer. 2019;19(1):184.

12. Marchioli R, Finazzi G, Landolfi R, Kutti J, Gisslinger H, Patrono C, Marilus R, Villegas A, Tognoni G, Barbui T. Vascular and neoplastic risk in a large cohort of patients with polycythemia vera. J Clin Oncol. 2005;23(10):2224-32.

13. Barbui T, Carobbio A, Rumi E, Finazzi G, Gisslinger H, Rodeghiero F, Randi ML, Rambaldi A, Gisslinger B, Pieri L, Bertozzi I, Casetti I, Pardanani A, Passamonti F, Vannucchi AM, Tefferi A. In contemporary patients with polycythemia vera, rates of thrombosis and risk factors delineate a new clinical epidemiology. Blood. 2014;124(19):3021-3.

14. Marchioli R, Finazzi G, Specchia G, Cacciola R, Cavazzina R, Cilloni D, De Stefano V, Elli E, Iurlo A, Latagliata R, Lunghi F, Lunghi M, Marfisi RM, Musto P, Masciulli A, Musolino C, Cascavilla N, Quarta G, Randi ML, Rapezzi D, Ruggeri M, Rumi E, Scortechini AR, Santini S, Scarano M, Siragusa S, Spadea A, Tieghi A, Angelucci E, Visani G, Vannucchi AM, Barbui T, CYTO-PV Collaborative Group. Cardiovascular events and intensity of treatment in polycythemia vera. N Engl J Med. 2013;368(1):22-33.

15. Harrison CN, Campbell PJ, Buck G, Wheatley K, East CL, Bareford D, Wilkins BS, van der Walt JD, Reilly JT, Grigg AP, Revell P, Woodcock BE, Green AR, United Kingdom Medical Research Council Primary Thrombocythemia 1 Study. Hydroxyurea compared with anagrelide in high-risk essential thrombocythemia. N Engl J Med. 2005;353(1):33-45.

16 Gisslinger H, Gotic M, Holowiecki J, Penka M, Thiele J, Kvasnicka HM, Kralovics R, Petrides PE, ANAHYDRET Study Group. Anagrelide compared with hydroxyurea in WHO-classified essential thrombocythemia: the ANAHYDRET Study, a randomized controlled trial. Blood. 2013;121(10):1720-8.

17. Godfrey AL, Campbell PJ, MacLean C, Buck G, Cook J, Temple J, Wilkins BS, Wheatley K, Nangalia J, Grinfeld J, McMullin MF, Forsyth C, Kiladjian JJ, Green AR, Harrison CN, United 
Kingdom Medical Research Council Primary Thrombocythemia-1 Study; United Kingdom National Cancer Research Institute Myeloproliferative Neoplasms Subgroup; French Intergroup of Myeloproliferative Neoplasms; the Australasian Leukaemia and Lymphoma Group. Hydroxycarbamide plus aspirin versus aspirin alone in patients with essential thrombocythemia age 40 to 59 years without high-risk features. J Clin Oncol. 2018;36(34):3361-9.

18. Barbui T, Carobbio A, Cervantes F, Vannucchi AM, Guglielmelli P, Antonioli E, Alvarez-Larrán A, Rambaldi A, Finazzi G, Barosi G. Thrombosis in primary myelofibrosis: incidence and risk factors. Blood. 2010;115(4):778-82.

19. Hultcrantz M, Björkholm M, Dickman PW, Landgren O, Derolf ÅR, Kristinsson SY, Andersson TML. Risk for arterial and venous thrombosis in patients with myeloproliferative neoplasms: a population-based cohort study. Ann Intern Med. 2018;168(5):317-25.

20. Mesa R, Jamieson C, Bhatia R, Deininger MW, Gerds AT, Gojo I, Gotlib J, Gundabolu K, Hobbs G, Klisovic RB, Kropf P, Mohan SR, Oh S, Padron E, Podoltsev N, Pollyea DA, Rampal R, Rein LA, Scott B, Snyder DS, Stein BL, Verstovsek S, Wadleigh M, Wang ES, Bergman MA, Gregory KM, Sundar H. Myeloproliferative neoplasms, version 2.2017, NCCN Clinical Practice Guidelines in Oncology. J Natl Compr Canc Netw. 2016;14(12):1572-611.

21. Barbui T, Tefferi A, Vannucchi AM, Passamonti F, Silver RT, Hoffman R, Verstovsek S, Mesa R, Kiladjian JJ, Hehlmann R, Reiter A, Cervantes F, Harrison C, Mc Mullin MF, Hasselbalch HC, Koschmieder S, Marchetti M, Bacigalupo A, Finazzi G, Kroeger N, Griesshammer M, Birgegard G, Barosi G. Philadelphia chromosome-negative classical myeloproliferative neoplasms: revised management recommendations from European LeukemiaNet. Leukemia. 2018;32(5):1057-69.

22. Barbui T, Finazzi G, Carobbio A, Thiele J, Passamonti F, Rumi E, Ruggeri M, Rodeghiero F, Randi ML, Bertozzi I, Gisslinger H, Buxhofer-Ausch V, De Stefano V, Betti S, Rambaldi A, Vannucchi AM, Tefferi A. Development and validation of an International Prognostic Score of thrombosis in World Health Organization-essential thrombocythemia (IPSET-thrombosis). Blood. 2012;120(26):5128-33.

23. Barbui T, Vannucchi AM, Buxhofer-Ausch V, De Stefano V, Betti S, Rambaldi A, Rumi E, Ruggeri M, Rodeghiero F, Randi ML, Bertozzi I, Gisslinger H, Finazzi G, Carobbio A, Thiele J, Passamonti F, Falcone C, Tefferi A. Practice-relevant revision of IPSET-thrombosis based on 1019 patients with WHO-defined essential thrombocythemia. Blood Cancer J. 2015;5(11):e369.

24.• Barbui T, De Stefano V, Alvarez-Larran A, Iurlo A, Masciulli A, Carobbio A, Ghirardi A, Ferrari A, Cancelli V, Elli EM, Andrade-Campos MM, Kabat MG, Kiladjian JJ, Palandri F, Benevolo G, Garcia-Gutierrez V, Fox ML, Foncillas MA, Morcillo CM, Rumi E, Osorio S, Papadopoulos P, Bonifacio M, Cervantes KSQ, Serrano MS, Carreno-Tarragona G, Sobas MA, Lunghi F, Patriarca A, Elorza BN, Angona A, Mazo EM, Koschmieder S, Carli G, Cuevas B, Hernandez-Boluda JC, Abadia EL, Cirici BX, Guglielmelli P, Garrote M, Cattaneo D, Daffini R, Cavalca F, Bellosillo B, Benajiba L, Curto-Garcia N, Bellini M, Betti S, Harrison C, Rambaldi A, Vannucchi AM. Among classic myeloproliferative neoplasms, essential thrombocythemia is associated with the greatest risk of venous thromboembolism during COVID-19. Blood Cancer J. 2021;11(2):21. A multicenter series of MPN patients with COVID-19 analyzing risk factors for thrombosis.

25.•• Middeldorp S, Coppens M, van Haaps TF, Foppen M, Vlaar AP, Müller MCA, Bouman CCS, Beenen LFM, Kootte RS, Heijmans J, Smits LP, Bonta PI, van Es N. Incidence of venous thromboembolism in hospitalized patients with COVID-19. J Thromb
Haemost. 2020;18(8):1995-2002. A single-center series of COVID-19 patients analyzing the incidence of venous thromboembolism.

26. Mohamed MFH, Al-Shokri SD, Shunnar KM, Mohamed SF, Najim MS, Ibrahim SI, Elewa H, Abdalla LO, El-Bardissy A, Elshafei MN, Abubeker IY, Danjuma M, Dousa KM, Yassin MA. Prevalence of venous thromboembolism in critically ill COVID-19 patients: systematic review and meta-analysis. Front Cardiovasc Med. 2021;7:598846.

27.• Al-Samkari H, Karp Leaf RS, Dzik WH, Carlson JCT, Fogerty AE, Waheed A, Goodarzi K, Bendapudi PK, Bornikova L, Gupta S, Leaf DE, Kuter DJ, Rosovsky RP. COVID-19 and coagulation: bleeding and thrombotic manifestations of SARS-CoV-2 infection. Blood. 2020;136(4):489-500. A multicenter series of COVID-19 patients analyzing the rates of bleeding and thrombosis.

28. Gratz J, Wiegele M, Maleczek M, Herkner H, Schöchl H, Chwala E, Knöbl P, Schaden E. Risk of clinically relevant venous thromboembolism in critically ill patients with COVID19: a systematic review and meta-analysis. Front Med (Lausanne). 2021;8:647917.

29. Lu YF, Pan LY, Zhang WW, Cheng F, Hu SS, Zhang X, Jiang HY. A meta-analysis of the incidence of venous thromboembolic events and impact of anticoagulation on mortality in patients with COVID-19. Int J Infect Dis. 2020;100:34-41.

30.• Puelles VG, Lütgehetmann M, Lindenmeyer MT, Sperhake JP, Wong MN, Allweiss L, Chilla S, Heinemann A, Wanner N, Liu S, Braun F, Lu S, Pfefferle S, Schröder AS, Edler C, Gross O, Glatzel M, Wichmann D, Wiech T, Kluge S, Pueschel K, Aepfelbacher M, Huber TB. Multiorgan and renal tropism of SARS-CoV-2. N Engl J Med. 2020;383(6):590-2. SARS-CoV-2 viral load in autopsy different tissue samples obtained from patients who had died from COVID-19.

31.• Varga Z, Flammer AJ, Steiger P, Haberecker M, Andermatt R, Zinkernagel AS, Mehra MR, Schuepbach RA, Ruschitzka F, Moch H. Endothelial cell infection and endotheliitis in COVID-19. Lancet. 2020;395(10234):1417-8. Endothelial cell involvement of SARS-CoV-2 across vascular beds of different organs in a series of patients with COVID-19.

32. Rayes J, Jenne CN. Platelets: bridging thrombosis and inflammation. Platelets. 2021;32(3):293-4.

33. Martin K. Risk factors for and management of MPN-associated bleeding and thrombosis. Curr Hematol Malig Rep. 2017;12(5):389-96.

34. Marchandot B, Trimaille A, Curtiaud A, Matsushita K, Jesel L, Morel O. Thromboprophylaxis: balancing evidence and experience during the COVID-19 pandemic. J Thromb Thrombolysis. 2020;50(4):799-808.

35• Spyropoulos AC, Levy JH, Ageno W, et al. ; Subcommittee on Perioperative, Critical Care Thrombosis, Haemostasis of the Scientific, Standardization Committee of the International Society on Thrombosis and Haemostasis. Scientific and Standardization Committee communication: clinical guidance on the diagnosis, prevention, and treatment of venous thromboembolism in hospitalized patients with COVID-19. J Thromb Haemost. 2020;18(8):1859-1865. Clinical guidance for prevention and treatment of venous thromboembolism in COVID-19 patients from the ISTH.

36. Moores LK, Tritschler T, Brosnahan S, et al. Prevention, diagnosis, and treatment of VTE in patients with coronavirus disease 2019: CHEST Guideline and Expert Panel Report. Chest. 2020;158(3):1143-63. Clinical guidance for prevention and treatment of venous thromboembolism in COVID-19 patients from CHEST.

37. Cuker A, Tseng EK, Nieuwlaat R, Angchaisuksiri P, Blair C, Dane K, Davila J, DeSancho MT, Diuguid D, Griffin DO, Kahn 
SR, Klok FA, Lee AI, Neumann I, Pai A, Pai M, Righini M, Sanfilippo KM, Siegal D, Skara M, Touri K, Akl EA, Bou Akl I, Boulos M, Brignardello-Petersen R, Charide R, Chan M, Dearness K, Darzi AJ, Kolb P, Colunga-Lozano LE, Mansour R, Morgano GP, Morsi RZ, Noori A, Piggott T, Qiu Y, Roldan Y, Schünemann F, Stevens A, Solo K, Ventresca M, Wiercioch W, Mustafa RA, Schünemann HJ. American Society of Hematology 2021 guidelines on the use of anticoagulation for thromboprophylaxis in patients with COVID-19. Blood Adv. 2021;5(3):872-88. Clinical guidance for prevention and treatment of venous thromboembolism in COVID-19 patients from the ASH.

38. Kaptein FHJ, Stals MAM, Huisman MV, Klok FA. Prophylaxis and treatment of COVID-19 related venous thromboembolism. Postgrad Med. 2021:1-9.

39. Klok FA, Kruip MJHA, van der Meer NJM, Arbous MS, Gommers DAMPJ, Kant KM, Kaptein FHJ, van Paassen J, Stals MAM, Huisman MV, Endeman H. Incidence of thrombotic complications in critically ill ICU patients with COVID-19. Thromb Res. 2020;191:145-7.

40. Martinelli I, Ciavarella A, Abbattista M, Aliberti S, De Zan V, Folli C, Panigada M, Gori A, Artoni A, Ierardi AM, Carrafiello G, Monzani V, Grasselli G, Blasi F, Peyvandi F. Increasing dosages of low-molecular-weight heparin in hospitalized patients with Covid-19. Intern Emerg Med. 2021:1-7. https://doi.org/ 10.1007/s11739-020-02585-9.

41.• Parisi R, Costanzo S, Di Castelnuovo A, de Gaetano G, Donati MB, Iacoviello L. Different anticoagulant regimens, mortality, and bleeding in hospitalized patients with COVID-19: a systematic review and an updated meta-analysis. Semin Thromb Hemost. 2021. https://doi.org/10.1055/s-0041-1726034. A systematic review and meta-analysis of the impact of different anticoagulant regimens on mortality and bleeding in patients with COVID-19.

42.• INSPIRATION Investigators, Sadeghipour P, Talasaz AH, Rashidi F, Sharif-Kashani B, Beigmohammadi MT, Farrokhpour M, Sezavar SH, Payandemehr P, Dabbagh A, Moghadam KG, Jamalkhani S, Khalili H, Yadollahzadeh M, Riahi T, Rezaeifar P, Tahamtan O, Matin S, Abedini A, Lookzadeh S, Rahmani H, Zoghi E, Mohammadi K, Sadeghipour P, Abri H, Tabrizi S, Mousavian SM, Shahmirzaei S, Bakhshandeh H, Amin A, Rafiee F, Baghizadeh E, Mohebbi B, Parhizgar SE, Aliannejad R, Eslami V, Kashefizadeh A, Kakavand H, Hosseini SH, Shafaghi S, Ghazi SF, Najafi A, Jimenez D, Gupta A, Madhavan MV, Sethi SS, Parikh SA, Monreal M, Hadavand N, Hajighasemi A, Maleki M, Sadeghian S, Piazza G, Kirtane AJ, Van Tassell BW, Dobesh PP, Stone GW, Lip GYH, Krumholz HM, Goldhaber SZ, Bikdeli B. Effect of intermediate-dose vs standard-dose prophylactic anticoagulation on thrombotic events, extracorporeal membrane oxygenation treatment, or mortality among patients with COVID-19 admitted to the intensive care unit: the INSPIRATION randomized clinical trial. JAMA. 2021:e214152.
A randomized controlled trial on the effects of intermediate-dose vs. standard-dose prophylactic anticoagulation in COVID-19 patients.

43. https://www.hematology.org/covid-19/covid-19-and-myeloproli ferative-neoplasms. Accessed 22 Apr 2021.

44. Boyle AJ, Di Gangi S, Hamid UI, Mottram LJ, McNamee L, White G, Cross LJ, McNamee JJ, O'Kane CM, McAuley DF. Aspirin therapy in patients with acute respiratory distress syndrome (ARDS) is associated with reduced intensive care unit mortality: a prospective analysis. Crit Care. 2015;19(1):109.

45- Kow CS, Hasan SS. Use of antiplatelet drugs and the risk of mortality in patients with COVID-19: a meta-analysis. J Thromb Thrombolysis. 2021:1-6. https://doi.org/10.1007/s11239-02102436-0. A meta-analysis of the impact of antiplatelet drugs on mortality and bleeding in patients with COVID-19.

46.• Chow JH, Khanna AK, Kethireddy S, Yamane D, Levine A, Jackson AM, McCurdy MT, Tabatabai A, Kumar G, Park P, Benjenk I, Menaker J, Ahmed N, Glidewell E, Presutto E, Cain S, Haridasa N, Field W, Fowler JG, Trinh D, Johnson KN, Kaur A, Lee A, Sebastian K, Ulrich A, Peña S, Carpenter R, Sudhakar S, Uppal P, Fedeles BT, Sachs A, Dahbour L, Teeter W, Tanaka K, Galvagno SM, Herr DL, Scalea TM, Mazzeffi MA. Aspirin use is associated with decreased mechanical ventilation, intensive care unit admission, and in-hospital mortality in hospitalized patients with coronavirus disease 2019. Anesth Analg. 2021;132(4):930-41. A multicenter observational study on the effect of aspirin on mechanical ventilation, admission to ICU, and mortality in COVID-19 patients.

47. Patti G, Lio V, Cavallari I, Gragnano F, Riva L, Calabrò P, Di Pasquale G, Pengo V, Rubboli A, Italian Study Group on Atherosclerosis, Thrombosis, Vascular Biology. Questions and Answers on Practical Thrombotic Issues in SARS-CoV-2 Infection: A Guidance Document from the Italian Working Group on Atherosclerosis, Thrombosis and Vascular Biology. Am J Cardiovasc Drugs. 2020;20(6):559-70.

48. Meyer SC, Steinmann E, Lehmann T, Muesser P, Passweg JR, Skoda RC, Tsakiris DA. Anti-platelet factor 4/heparin antibody formation occurs endogenously and at unexpected high frequency in polycythemia vera. Biomed Res Int. 2017;2017:9876819.

49. Castelli R, Gallipoli P, Schiavon R, Teatini T, Deliliers GL, Bergamaschini L. High prevalence of heparin induced thrombocytopenia with thrombosis among patients with essential thrombocytemia carrying V617F mutation. J Thromb Thrombolysis. 2018;45(1):106-13.

Publisher's Note Springer Nature remains neutral with regard to jurisdictional claims in published maps and institutional affiliations. 